\title{
INVESTIGATING THE IMPACT OF CONFLICT MANAGEMENT ON EMPLOYEE'S PERFORMANCE: A STUDY BASED ON TOOL BOX OF CONFLICT ANALYZING MODEL BY FURLONG
}

\author{
Muhammad Tariq \\ Deputy Director-ORIC Institute of Business and Technology, Karachi \\ Seema Yasmin \\ Research Student, Institute of Business and Technology, Karachi, Pakistan
}

\begin{abstract}
This study investigated the impact of Conflict Management on Employee's Performance and implementing the Furlong 'tool box of conflict analyzing model to find out how conflict will be resolved easily, effectively and improve the overall Employee's performance. This study developed the survey research design. 200 respondents were selected of different organizations for the study. Questionnaire was used to collect primary data. Hypothesis was tested through regression analysis. The findings of the research revealed that effective management tools develop the employee's performance in the organization. Furlong tool box of conflict analyzing model provide favorable outcomes in the perspectives of Trust, Behavior, Avoidance and Emotions. The result and outcomes of my research provide a structure and importance of application of Conflict management in cooperation to find out how will minimize the clash between the employees and subordinates for the betterment of the employee's performance. The other organizations can also get benefits of this research.
\end{abstract}

Keywords: Conflict management, Employee's Performance, Efficiency, Effectiveness

Jel Classification: M10

*The material presented by the author does not necessarily portray the view point of the editors and the management of the Institute of Business \& Technology - IBT

1. Muhammad Tariq : muhammad.tariq1985@gmail.com

CIBT-JBS is published by the Institute of Business \& Technology - IBT

Main Ibrahim Hydri Road, Korangi Creek, Karachi-75190, Pakistan. 


\section{INTRODUCTION}

Conflict a kind of simple life of an individual and management. It influences on employee or individual performance. It is unbelievable to pack the critical points of conflict in an exact definition since it might take a few different kinds and forms. According to Fadipe and Oluchukwu (2000) conflict is a type of contradiction in a formation between two employees or number of employees who have reason to collaborate formally or casually. According to Albert (2001) conflict is arise when productively talked between the employees and by the gatherings and parties in terms for settlement came to. Susan R Madsen, Duane Miller and Cameron R John (2005) conflict fundamental fight between two or more employee and groups of employees over perfect objectives and targets. Conflict is a disagreement and contradiction. Conflict emerges employee or between two or more groups of employee inside an organization.

\section{TOOL BOX OF CONFLICT ANALYSING MODEL:}

Gary T. Furlong (2005) established on his conflict tool compartment or analyzing models, The Tool Box will profile 8 conflict management or resolution models.

Furlong's conflict analyzing models are as follows:

1. Circle of conflict

2. Triangle of Satisfaction model

3. Boundary Model

4. Interest/right/power model

5. $\quad$ Trust model

6. Dimensions model

7. Social style model

8. Moving beyond model

These models define large numbers of different various approaches to see at conflict. Each and every model brings an alternate and conceivably helpful angle on the worker performance.

The Furlong's tool box models of conflicts are as follows:-

\section{Circle of conflict model:}

This model indicates the value, interest, mood and relationship in managing conflict.

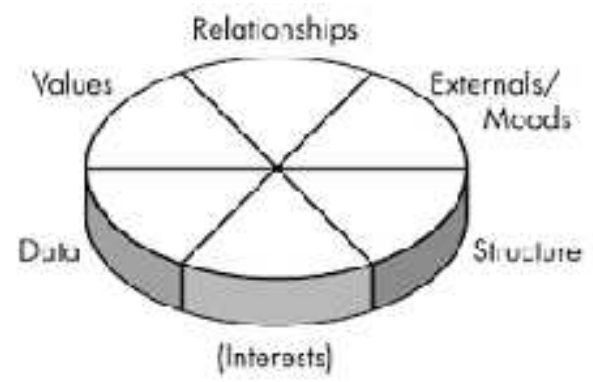

Source: Furlong, G. T. (2005). The conflict resolution toolbox: Circle of conflict 


\section{Triangle of satisfaction model:-}

Examine 3 types of conflict managers such as emotion, process and result.

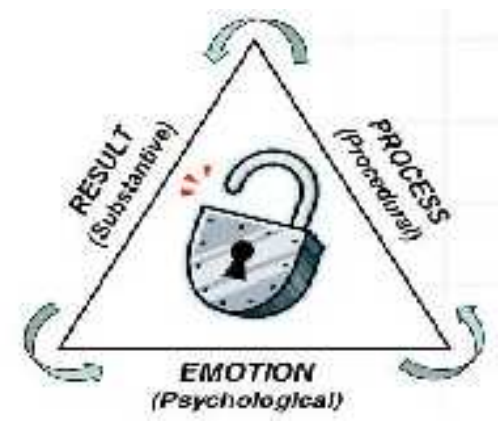

Source: Furlong, G. T. (2005). The conflict resolution toolbox: Triangle satisfaction.

\section{Boundary Model:-}

Explore the impact of reject and accept of social boundaries, behavior and conflict over the NORMS.

(Acceptable Minimum)

Behavior

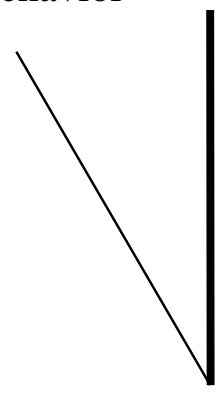

Boundaries (Authority)

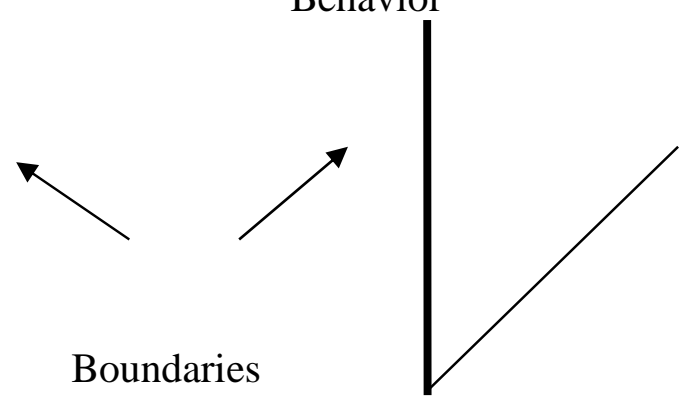

(Acceptable Maximum)

Behavior

Norm

\section{Expanded Norm}

Source: Furlong, G. T. (2005). The conflict resolution toolbox: Boundary

\section{Power, interest and rights Model:-}

Attention on the process with conflict based on power, interest and right.

Dispute

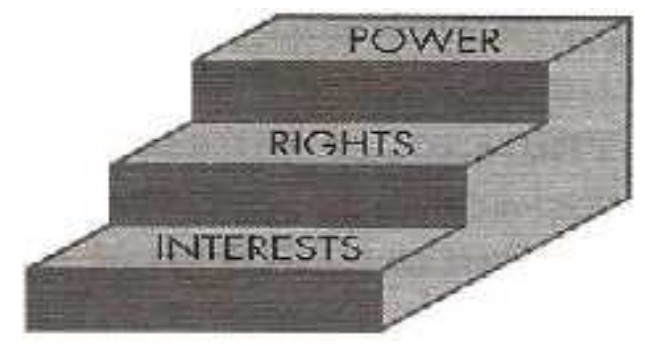

Source: Furlong, G. T. (2005). The conflict resolution toolbox: PRI 


\section{Trust Model:}

Examine the breaking of trust and strategies for the reshaping of trust.

\section{Triggering}

\section{Event}

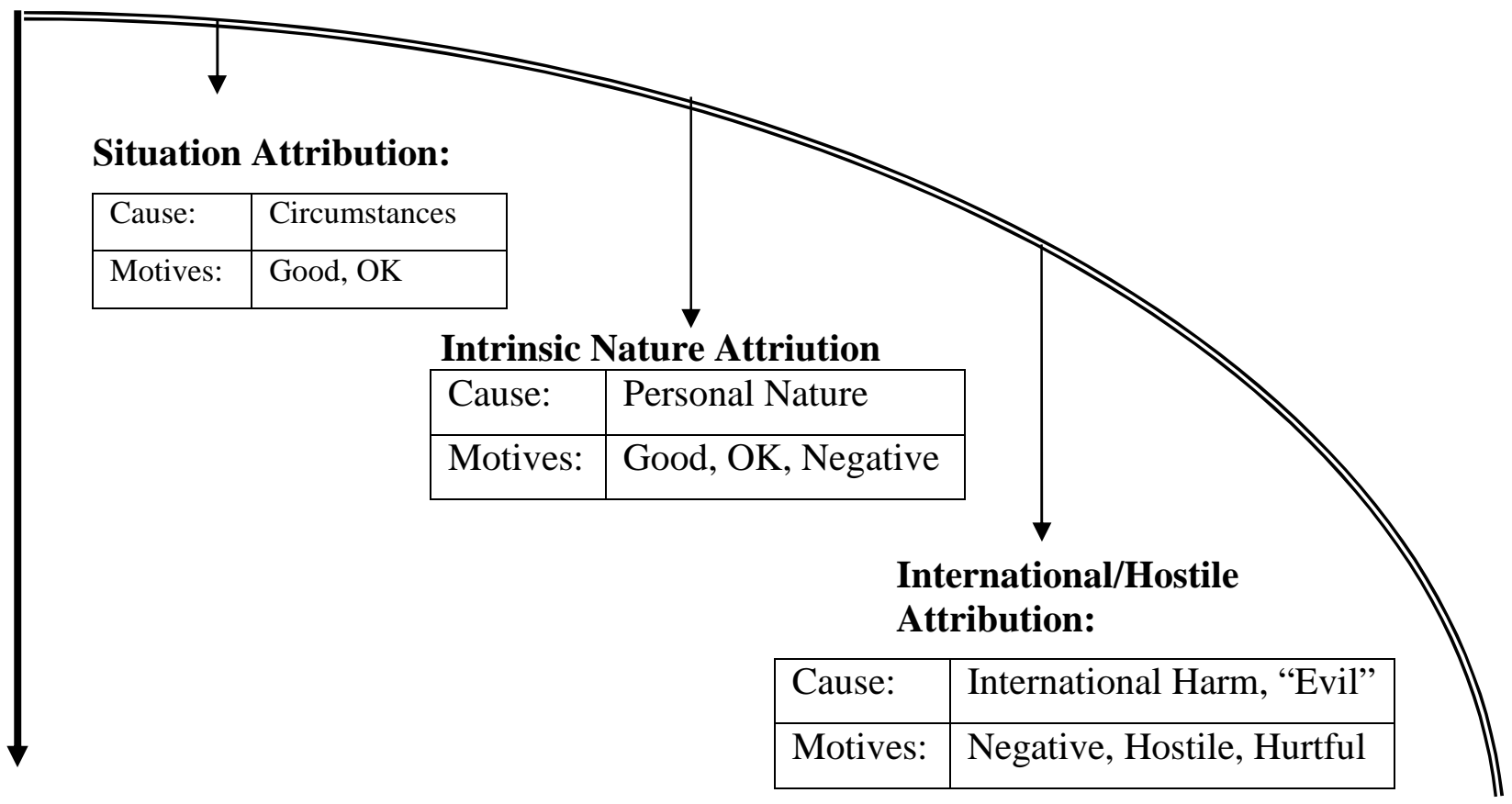

\section{Decreasing Level of Trust}

Source: Furlong, G. T. (2005). The conflict resolution toolbox: Trust

\section{Dimensions Model:}

Highlight the role of cognitive, emotional and behavioral dimensions in conflict.

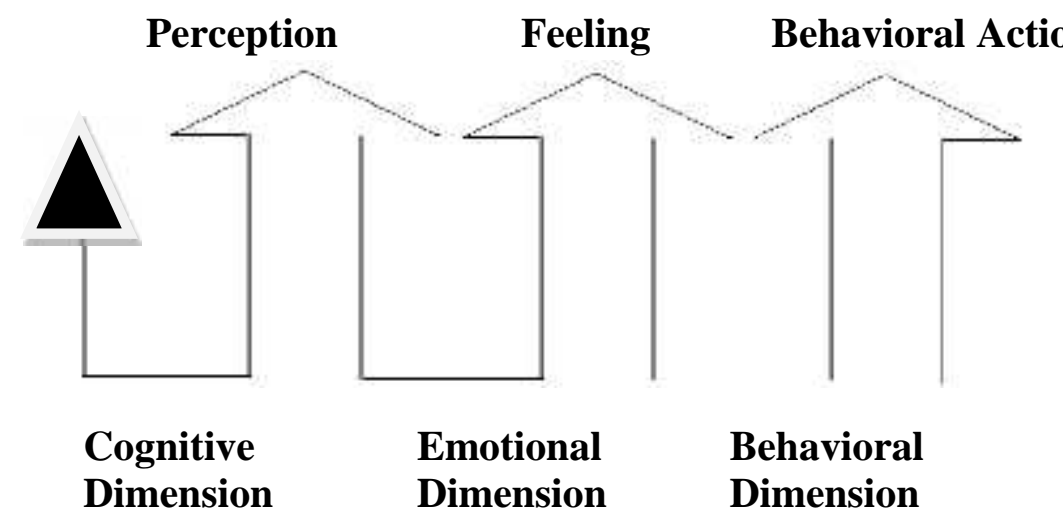

Source: Furlong, G. T. (2005). The conflict resolution toolbox: Dimension 


\section{Social Style Models:-}

Attentions on the significance and differences of evaluating 4 major behavior kinds: Analytic, Amiable, Driving and Expressive personality.

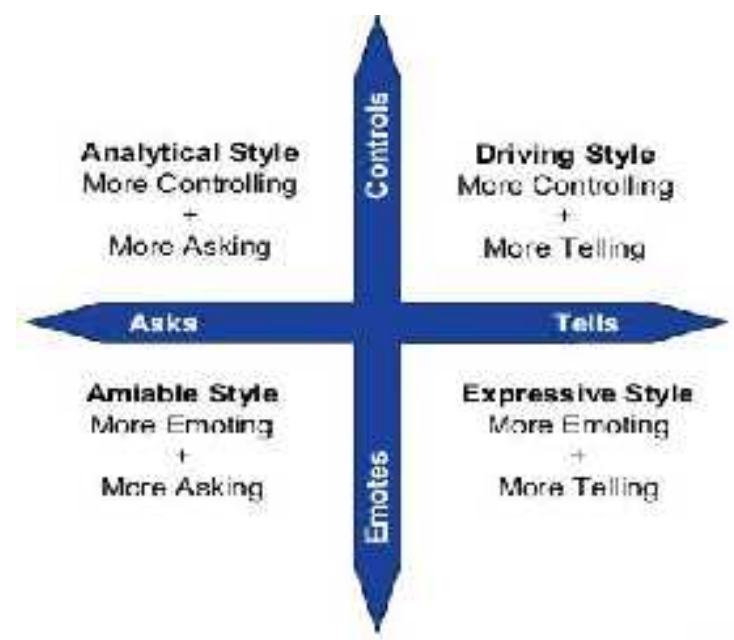

Source: Furlong, G. T. (2005). The conflict resolution toolbox: Social Style

\section{Moving Beyond Models}

Explore the 3 important stages and strategies for moving beyond conflict models like Anger, Denial and acceptance.

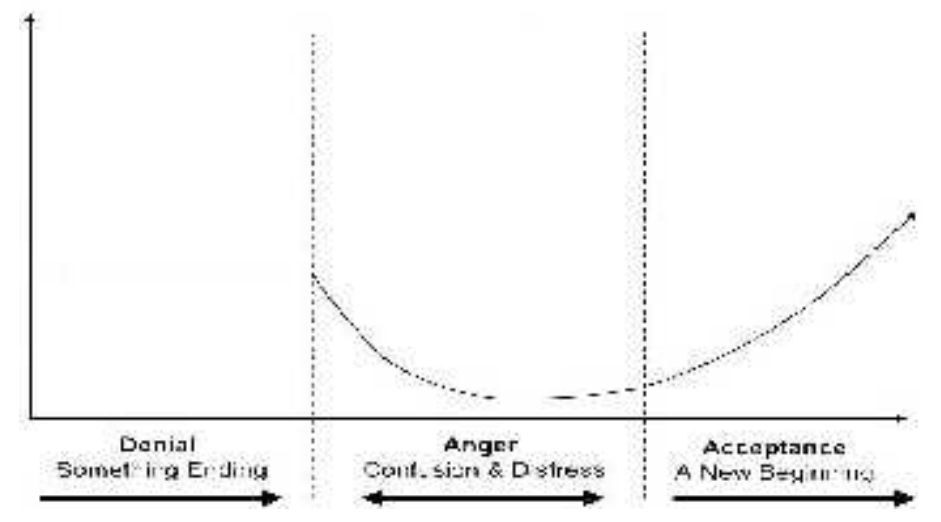

Source: Furlong, G. T. (2005). The conflict resolution toolbox: Moving

\section{Problem Statement:}

Conflict produce in a company when employees accomplish their targets are threatened by the action of other person. Conflict usually arises in the organization between the employees and managers as well as coworkers for the purpose of personal interest and wants. This study define that conflict branches from irrelevant of target and if it continue it will damage the organization as well as destroy the employee performance. 


\section{Significance of the Study:}

My study provides:

- $\quad$ To highlight the main reason of all conflict.

- $\quad$ Define every model focus to what type of situation can be helpful and intervening forces are likely to help.

- Determine clear way and path to specified action to resolve a conflict efficiently.

- $\quad$ The Furlong's Conflict Resolution Toolbox Models creates to solve large number of conflict. All the levels of employees and supervisors and owners shall have models they want for successful conflict management.

\section{Objectives of the Study:}

. The purpose of this research is:

- $\quad$ To find out how conflict will be resolved easily and effectively.

- $\quad$ To find out main causes of conflict.

- $\quad$ To find out the influence the conflict management on performance.

- $\quad$ To define conflict management tools by Furlong's tool box of Conflict resolving model.

Unfortunately, the gap to be appear in this research identifying the skill and leadership are much efficient in contracting conflict between employees before the dispute escalates to much deeply attitude acquiring disciplinary action. Furlong Tool Box of conflict resolution model help employees conflict problem which emerges in the organization as well as help to employees performance efficiently

\section{Hypotheses of the Study:}

H1: Trust is insignificant positive impact on Employee's Performance.

H2: Avoidance is insignificant negative impact on Employee's Performance.

H3: Behavior is significant negative impact on Employee's Performance.

H4: Emotion is significant positive impact on Employee's Performance.

\section{LITERATURE REVIEW}

One essential goal of organization is to define an environment in which employee and groups could understand with each other to achieve the target and the target of the association. The most important problem in the organization is employee and management competes for small sources status and rights. Conflict concepts are very essential for every level of managers. It is totally concerned with the individual behavior and perception. According to Thomas (1976) conflict is a process which one employee understands and the other has frustrated and is to frustrated concern. Rahim (1986) conflict is a untruth, disagreement between and within social network of the people. Bob Dick (1987) stated that conflict management is a systematic assumptions to group building and mediated and non mediated conflict solution Campbell, McCloy, Opplers and Sager (1993) Employee performance is an activity that help out the company's goals are related to the values of organizational employees. Jordan and Troth (2002) conflict management theory is essential for owners and managers to recreate their psychological and mental criteria. Conflict resolution is the path of solving conflict by addressing and dialoguing at minimum of one 
side's concern. Kyle Oppenhuzen (2003),concluded that 5 points to avoid conflict like: Recognize the actual source of conflict, Be attention of generation gap, Aware the factor of conflict, Stay a balance head of conflict, Activity related conflict to use. Furlong (2005) Trust model solve the difficult problems of how TRUST is arises, how is perform and how lack of trust influence the employee performance. We spending lives filled with boundaries. Employee can apply positive behavior to resolve the conflict between the groups. Following are the causes of conflicts on employee:

- Increase smoking

- $\quad$ Alcoholic

- overeating

- Anger

- Low communication

- $\quad$ Aggressiveness

Kurtzberberg et al. (2005) brought forward that research has confident that there are three important types of conflict. First is based on working process that how much working process is performed and how much responsibilities are created. Second is based on relationship based conflict where communication and relation between employees and subordinates. Third is based on task conflict where disagreement about the work itself and causes the problems.

George Kohlrieser (2007) assumed that it is fact that we can apply managed conflict to find many fruitful sources to employees and organization. Actually conflict management is the important point of innovation. Well managed, it can help employee to be more advancement and can create strong relation, build effective group and increase better performance. Runde and Flanagan (2007) pointed out a few benefits that are necessary for the conflict management leader: Control aggressiveness, Hesitating conflict management, Critical of ideas, Hard to deal criticism. Ideas focus on best results such as: Extra work to understand all sides of problems, Listening to others, Encouraging creativity and clear and sure. Gothenburg, Sweden (2011) developed an approach to conflicts that built the problem solving process more effective provides manager and the team a higher possibility to find the target necessities. Odigwe (2013) thought that since conflict is invertible in the performance of the employees, its management find rather it will create good or bad impact on the organizational performance .Conflict management process is a remarkable obstructive procedure which can be implemented in a numerous diverse paths in associations.

Conflict analysis models, they are effective at easiest interactions as well as giving us beneficial guidance, it should be daily bases application by practitioners in the field, and should be a important part of any employees training. So how much training in this type of analyzing model, in frameworks for analyzing and understanding the center causes of conflict, it is included in most conflict resolution or mediation courses? Obviously no.

\section{Conflict:}

Conflict is disagreement, it starts when the individual trust that other may clash individuals works. Conflict might produce of the individuals' disagreement to increase output on the other hand employees represents are out to sure the linear efficient situation of working for their individual's clash can also produce as a output of conflict of performance. 


\section{Conflict Management:}

This is the essential point of this research. It can be explain the technique, tools, style to resolving conflict. A right thinking to organization clash defines the method of managing confli ACTIVITY FOR CONFLICT MANAGEMENT: There are many activities applied in resolving conflict, and importantly all instructions to reason like that:

- $\quad$ Handling the matter

- Handling the problems

- Handling the relation

- $\quad$ Editing the employee involved

\section{EMPLOYEE PERFORMANCE:}

Kaplan and Norton (1992) define convinced that the mixing of measurement which a company must use to reach employee performance must be based around 4 different criteria.

- $\quad$ Financial activity

- Customer activity

- Internal business activity

- Innovation and learning criteria

\section{METHODOLOGY}

\section{Data Collection:}

Primary data is collected through Questionnaires. Questionnaire was discovered by the Statistical Society of London in (1938) based on liker scale like 1: supposed to strongly disagree, 2: Disagree, 3: Neutral, 4: Strongly agree 5: Agree. The source to collect data involves different position and level of the employees of different firms. Each option is assigned with a value that shall be used in one sample test. The number starts from strongly disagree; given, disagree is given value 2 . Similarly 3 is used for Neutral, 4 is assigned to agree and 5 for strongly agree.

\section{Sampling Technique and Sample Size}

Convenient sampling are used which the 200 participants in this research different level of the employees of the companies. A range of survey is Karachi Pakistan. The sample size of this research consists of 200 participants of different firms. The professionals includes; operation managers, senior managers, Production managers, and different level of the employee of the companies.

\section{Statistical Test:}

Linear Regression Analysis is used to analyze the data. The categorical data (on liker scale) which has been collected via questionnaire shall be statistically analyzed. Before applying statistical test the reliability test has been applied through Cronchbach Alpha to test the reliability of data series. The Regression Model has been applied after the satisfaction of reliability criteria of data series. The procedure may be summarized as: the average of each 2 questions of related independent variable has been made to represent it as one question has been made with define the relation between dependent and independent variable. The ratio of questions between independent and dependent variables are $2+1$. 


\section{Research Model and conceptual Framework}

This study investigates effect of various perspectives used in Conflict Management on Employee's Performance. The Basic Regression Model is as:

$$
Y=\beta_{0}+\beta_{1} \chi_{1}+\beta_{2} \chi_{2}+\beta_{3} \chi_{3}+\beta_{4} \chi_{4}+\ldots \ldots \ldots \ldots \ldots .+\mu \ldots \ldots \ldots \ldots \ldots . .(i)
$$

This study requires developing a model to calculate the impact of Conflict Management on Employee's Performance (EP). We have taken following perspectives of Conflict Management which shall be used to test their effect on the Employee's Performance. Hence, these factors may be used as predictors in our Regression Model:

\section{Trust (TR)}

\section{Behavior (BV)}

Avoidance (AV)

\section{Emotions (EM)}

Therefore, the required model shall become as follows:

$E P=\beta_{0}+\beta_{1} T R+\beta_{2} B V+\beta_{3} A V+\beta_{4} E M$

\section{Conceptual Framework}

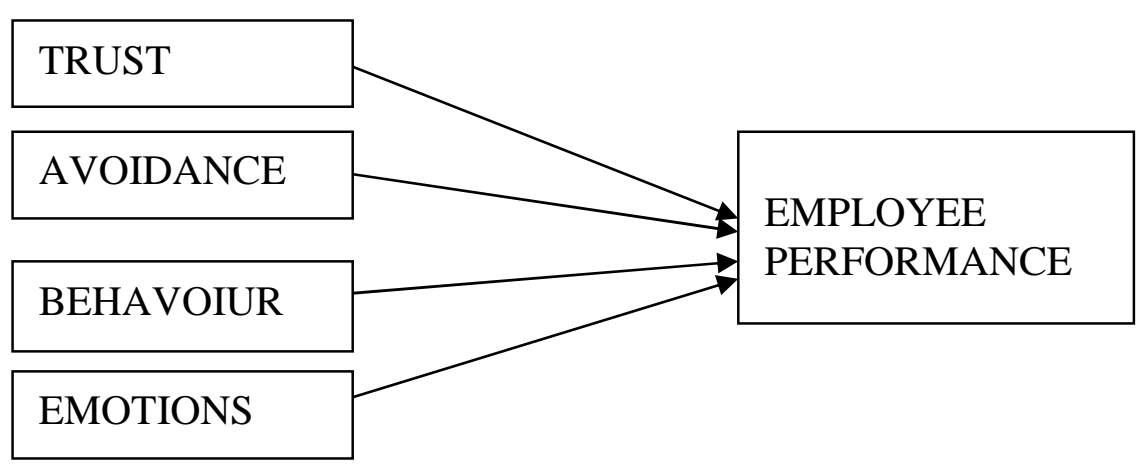

Sources: This model is based on Furlong's Tool Box of Conflict Management.

\section{RESULT OF THE STUDY}

\section{Reliability and Validity Model: Interpretation of Reliability Test and Anova:}

The reliability test is used to test the reliability of categorical data which shall be applied as scale in Regression analysis. Table. 1 represents the individual reliability of each variable and then overall reliability, i.e. collectively all the variables are tested using Cronch bach's alpha. 
Table 1 behavior

Reliability Test

\section{Reliability Statistics}

\begin{tabular}{|c|c|c|}
\hline VARIABLES & $\begin{array}{ll}\text { CRONCH } & \text { BACH'S } \\
\text { ALPHA } & \end{array}$ & NO. OF ITEMS \\
\hline TRUST & .820 & 2 \\
\hline BEHAVIOR & .762 & 2 \\
\hline AVOIDANCE & .658 & 2 \\
\hline EMOTIONS & .762 & 2 \\
\hline $\begin{array}{l}\text { EMPLOYEE } \\
\text { PERFORMANCE }\end{array}$ & .599 & 4 \\
\hline OVERALL & .846 & 12 \\
\hline
\end{tabular}

Table 2 shows that the value of adjusted $\mathrm{R}$ square is .698 which is upto $70 \%$.

Table 3 shows the outcome of ANOVA test. The significance value is 0.00 which is less than 0.05 as well as F value (116) is also significant showing that ANOVA test is significant.

Table 2 Model Summary

\begin{tabular}{|l|l|l|l|l|}
\hline Model & R & R Square & Adjusted R Square & Std. Error of the Estimate \\
\hline 1 & $.839^{\mathrm{a}}$ & .704 & .698 & .40319 \\
\hline
\end{tabular}

\section{Table 3: ANOVA}

\begin{tabular}{|l|l|l|l|l|l|l|}
\hline \multicolumn{2}{|l|}{ Model } & Sum of Squares & Df & Mean Square & F & Sig. \\
\hline \multirow{4}{*}{1} & Regression & 75.531 & 4 & 18.883 & 116.159 & $.000^{\mathrm{b}}$ \\
\cline { 2 - 7 } & Residual & 31.699 & 195 & .163 & & \\
\cline { 2 - 5 } & Total & 107.230 & 199 & & & \\
\hline
\end{tabular}

a.

b.

Emotions
Dependent Variables: Emp_Per

Predictors: (Constant), Trust, Behavior, Avoidance,

Based on the results of ANOVA and Reliability test the Regression model may be applied. We paste here the Regression Model which has been developed for our study:

$$
E P=\beta_{0}+\beta_{1} T R+\beta_{2} B V+\beta_{3} A V+\beta_{4} E M
$$

Table 4 provides the results of Regression model. The model to estimate the Employee's Performance due to efforts of conflict management tools would be as follows $E P=1.048+.090{ }_{1} T R+(.115) B V+(-.078) A V+(.736) E M$

The equation (and the results of Beta coefficients in table 4) depicts positive sign This endorses the positive effect of conflict management on the Employee's performance. 
Table No.4 Estimation of Employee performance

\begin{tabular}{|l|l|l|l|}
\hline Estimators & \multicolumn{3}{|l|}{ Employee Performance as dependant variable } \\
\hline & Beta & Sig value & T statistics \\
\hline Trust & 0.9 & .085 & 1.731 \\
\hline Behavior & -0.115 & 0.037 & -2.097 \\
\hline Avoidance & -0.078 & 0.164 & -1.397 \\
\hline Emotion & 0.736 & 0 & 13.916 \\
\hline C & 1.048 & 0 & 7.863 \\
\hline
\end{tabular}

Other Parameters are as:

$\begin{array}{ll}\checkmark & \text { Adjusted R Square .698 } \\ \checkmark & \text { F statistics 116.159 } \\ \checkmark & \text { N 200 }\end{array}$

H1: There is insignificant positive impact of Trust on Employee's Performance.

The sig value (.085 ) beta coefficient of Trust (TR) is more than 0.05 which shows it insignificance, this justifies that first hypothesis of the study is rejected.

H2: There is significant impact of Behavior on Employee's Performance.

The test is significant for the beta coefficient of Behavior (BV) since the Sig value (.037) which is less than 0.05; it means it is accepted that there is significant negative impact of Behavior on Employee's Performance.

H3: There is insignificant negative Impact of Avoidance on Employee's Performance.

The sig value (.164 ) of beta of the Avoidance (AV) is more than 0.05, but the hypothesis is rejected because the coefficient has negative sign.

H4: There is significant Positive impact of Emotions on Employee's Performance.

The sig value (.000 ) of beta of the Emotions (EM) is less than 0.05 which shows that the test is significant; therefore, hypothesis is accepted which shows that there is significant positive effect of Emotions on Employee's Performance (EP). 
Table 5: Hypothesis Assessment Summary

\begin{tabular}{|c|c|c|c|c|c|}
\hline Sr. No. & Hypothesis & Beta & $\begin{array}{l}\text { Sig. } \\
\text { Value }\end{array}$ & $\begin{array}{l}\text { T } \\
\text { Value }\end{array}$ & $\begin{array}{l}\text { Empirical } \\
\text { Results }\end{array}$ \\
\hline $\mathbf{H}_{1}$ & $\begin{array}{l}\text { There is significant effect of trust on } \\
\text { employee performance }\end{array}$ & .090 & 0.085 & 1.731 & Rejected \\
\hline $\mathbf{H}_{2}$ & $\begin{array}{l}\text { There is significant effect of behavior } \\
\text { on employee performance. }\end{array}$ & -.115 & 0.037 & $-\overline{2} \cdot 097$ & Accepted \\
\hline $\mathbf{H}_{3}$ & $\begin{array}{l}\text { There is significant } \begin{array}{l}\text { effect of } \\
\text { avoidance } \\
\text { performance. }\end{array} \\
\text { employee's }\end{array}$ & -.078 & -1.397 & .164 & Rejected \\
\hline $\mathbf{H}_{4}$ & $\begin{array}{l}\text { There is a significant effect of } \\
\text { emotions } \\
\text { performance. }\end{array}$ & .736 & 13.916 & .000 & Accepted \\
\hline
\end{tabular}

\section{DISCUSSION AND CONCLUSION}

\section{Discussion:}

My study has built the bridges to gap between conflict and employee's performance and go away from just one single model to present a complete toolbox - a variety of models that can be used to analyze, diagnose, and resolve conflict in any situation. The values of Beta in regression equation clear the performance of the employees in the perspective of conflict management tools. It defines mediators, negotiators, and managers to manage conflict how to simply and successfully understand and reaches the situations of conflict they face. My 4 dimensions Trust, Behavior, Avoidance and Emotions are interrelate of Conflict Resolution Toolbox which as a guide for employees and organization to learn, apply, test and practice with models that gain the reflective practitioner toward higher positions of competence and through to true artistry.

\section{Conclusion:}

My research wrap up that if the organization can successfully and capably manage conflict within its action, this will lead to high level of employees performance which will result into accomplishment of the organizational goals and objectives. Successfully managing conflict has a great outcome, allowing managers to create a place of work where employees can flourish.

\section{Policy Implication:}

Conflict exists in all organization and to a certain level highlight a positive replace of ideas and originality. However, counter-productive conflict can result in employee dissatisfaction, reduced productivity, and bad service to customer, absenteeism and increased Employee turnover, increased work-related stress or proceedings based on claims of aggravation or an unfriendly work atmosphere. The conflict management policy must build up open communication and safe environment for delivering differences of opinions. There should be a clear statement defending employees from reprisal for raising justifiable complaints and 
concerns using the conflict resolution process. . The respondents believe that implementation of Furlong tool box of conflict resolving model provides favorable outcomes. Especially the performance perspectives have significant positive effect over the Employee's Performance.

\section{Future Research:}

There are several things that the researcher found interesting for future research. The limitations of this research should be addressed in the light of findings that research conducted on conflict management might be applied to the further different organizations; there must be investigated according to requirements in future. As my research was limited to only 5 or 6 organization, using the different samples may produce different results in future. The collected data may be biased and could affect the accuracy of these results.. For the minimization of conflict in the organization it must have to need further research in this regards. My research is not enough to manage conflict in the individuals and organization. No doubt my research provided the some right way to manage dispute with the help o of Furlong's Tool Box of Conflict Analyzing model and try to enhance the employee's performance but it is important to do some further research in this regards. Finally, this study was conducted under strict time constraints. Data collection was difficult from the employees of different level in the organization. Many other areas were remaining untouched due to limited resources.

The major weakness of study is that it focuses on sample size which does not give a comprehensive view on conflicts due to constraint of time and so that research was carried out only on 5 organizations. For the minimization of conflict in the organization it must have to need further research in this regards. My research is not enough to manage conflict in the individuals and organization .No doubt my research provided the some right way to manage dispute between the employees with the help o of Furlong's Tool Box of Conflict Analyzing model and try to enhance the employee's performance but it is necessary to do some further research in this problem.

\section{REFERENCES:}

Albert, I. O. (2001). Introduction to third-part intervention in community conflicts. John Archers.

Beardsley, K., \& Lo, N. (2013). Third-party conflict management and the willingness to make concessions. Journal of Conflict Resolution, 0022002712467932.

Campbell, J. P., McCloy, R. A., Oppler, S. H., \& Sager, C. E. (1993). A Theory of Performance. In N. Schmitt \& W. C. Borman (Eds.), Employee Selection. New York: Jossey-Bass.

Dalmau, T., \& Dick, B. (1987). Politics, conflict and culture.

Furlong, G. T. (2005). The conflict resolution toolbox: Models \& maps for analyzing, diagnosing, and resolving conflict. Mississauga, Ont: J. Wiley \& Sons Canada.

Jordan, P. J., \& Troth, A. C. (2002). Emotional intelligence and conflict resolution: Implications for human resource development. Advances in developing human resources, 4(1), 62-79.

Kaplan, R. S., \& Norton, D. P. (2005). The balanced scorecard: measures that drive performance. Harvard business review, 83(7), 172.

Kohlrieser, G. (2007). Six essential skills for managing conflict. Perspectives for Managers, 149, 1-3. 
Kurtzberg, T. R., \& Mueller, J. S. (2005). The influence of daily conflict on perceptions of creativity: A longitudinal study. International Journal of Conflict Management, 16(4).

Madsen, S. R., John, C. R., \& Miller, D. (2005). Work-family conflict and health: A study of workplace, psychological, and behavioral correlates. Journal of Behavioral and Applied Management, 6(3), 225.

Oluchukwu, E. E. (2000). Staff Motivation Towards Effective Job Performance in Nigerian Schools. Management in Nigerian Education: Personal Administration and Quality in Education. Fadipe, JO and Ojedele, PK (eds) Vol, 25-39.

Rahim, M. A. (1986). Referent role and styles of handling interpersonal conflict. The Journal of social psychology, 126(1), 79-86.

Runde, C.E. and Flanagan T.A. (2007) Becoming a Conflict Competent Leader. SanFrancisco: Jossey-Bass.

Thomas, K. W., \& Schmidt, W. H. (1976). A survey of managerial interests with respect to conflict. Academy of Management journal, 19(2), 315-318.

Thorsson, S., Lindberg, F., Björklund, J., Holmer, B., \& Rayner, D. (2011). Potential changes in outdoor thermal comfort conditions in Gothenburg, Sweden due to climate change: the influence of urban geometry. International Journal of Climatology, 31(2), 324335.

Uchendu, C. C., Anijaobi-Idem, F. N., \& Odigwe, F. N. (2013). Conflict management and organisational performance in secondary schools in cross river state, Nigeria. Research Journal in Organizational Psychology and Educational Studies (RJOPES), 2(2), 67. 